\title{
Social-technical aspects in modern manufacturing
}

\author{
Przemysław Oborski \\ Warsaw University of Technology, \\ Institute of Manufacturing Technology, \\ ul. Narbutta 86, 02-524 Warsaw, Poland \\ e-mail: P.Oborski@wip.pw.edu.pl
}

\begin{abstract}
Manufacturing companies must compete on more and more global market. Continuos quality improvement, reduction of products' price and production series' shortening are necessary to be competitive. In such a situation development of production systems is necessary. It can be done only by development of all manufacturing systems' elements, like production methods, machines, process, control and information systems. An important part of manufacturing systems, very often not appreciated enough is human being. The paper focuses on the changing role of managers and machine operators. The problem of human decision quality, Artificial Intelligence support and Socio-Technical Design approach are discussed as well. The aim of the paper is to present the important factors that significantly influence balanced development of advanced manufacturing systems. The article is the result of the research project focused on co-operation improvement between machine operators and technical systems in manufacturing companies.
\end{abstract}

Keywords: manufacturing systems, human factor, computer integrated production, socio-technical design, man-machine interaction.

\section{Introduction}

Manufacturing industry plays an important role in the economic environment of most countries. In the time of growing international competition, manufacturing sector development has significant impact on the social and economic situation in industrialised countries. To survive on the market, companies must quickly react to market demands, increase quality and decrease prices of products. Improvement in 
productivity and quality is necessary. When we add to it the growing cost of manpower and increasing standard of life it become obvious that the new concepts of manufacturing must be applied. The advanced manufacturing should be based on recent achievements of manufacturing technology, electronics, software and information processing supported by artificial intelligence. The results of application of recent achievements are more effective, highly complicated and costly manufacturing systems and machines. In the industrial countries, the intensity of capital investment in the production has grown rapidly over the last years [1]. It results in more efficient and easier to use, but also more complex manufacturing systems. When add to it the fact that the number of working hours is decreasing continuously, it is obvious that employees directly involved in the manufacturing process play more important role than in the past.

\section{Social system in manufacturing}

Present manufacturing systems are very complex. They are widely supported by recent achievements of the computer technique and very often are highly automated, but they still require human operators and production managers. Since most of simple manipulation activities have been replaced by machines and technical systems, the role of human being became even more important than in the past. Their activity is consequently moving from the responsibility for simple manual tasks to the decision field. Moreover, in the time of high competition the penalties for wrong decisions are extremely high, what results in working under very high stress [2].

In recent years the work load is growing rapidly, at the same time the number of people working in average workshop is still decreasing. As a result of such a situation the significance of the machine operators increases, they are more and more responsible for production as a whole than for particular machine [1]. Machine operator can spend less time for operation on one machine, usually he or she is responsible for several machines in workshop. In a view of these facts machine tools need advanced control systems, that can control not only machine operation, but also supervise the manufacturing process and machine's condition.

The manager's role is changing as well. Present manufacturing systems operate in variable environment. The production must respond on the client demands, what results in shortening of production series. At the same time the production stocks are reduced 
to the minimum. In the light of this situation, managers are responsible not only for proper manufacturing process operation but also for particular products' realisation and for relations with suppliers and clients. When add to it that their number is also still decreasing [3], we can sharply see that there is less space for mistakes. Managers need the special information systems with the decision support that allow them focus more on difficult problems solving, then on the daily manufacturing system operation.

The role of machine operators and managers in the modern manufacturing systems are strictly connected. The incorporation of human operators into selected decision processes seams to be a key issue for the efficient management, at complex systems.

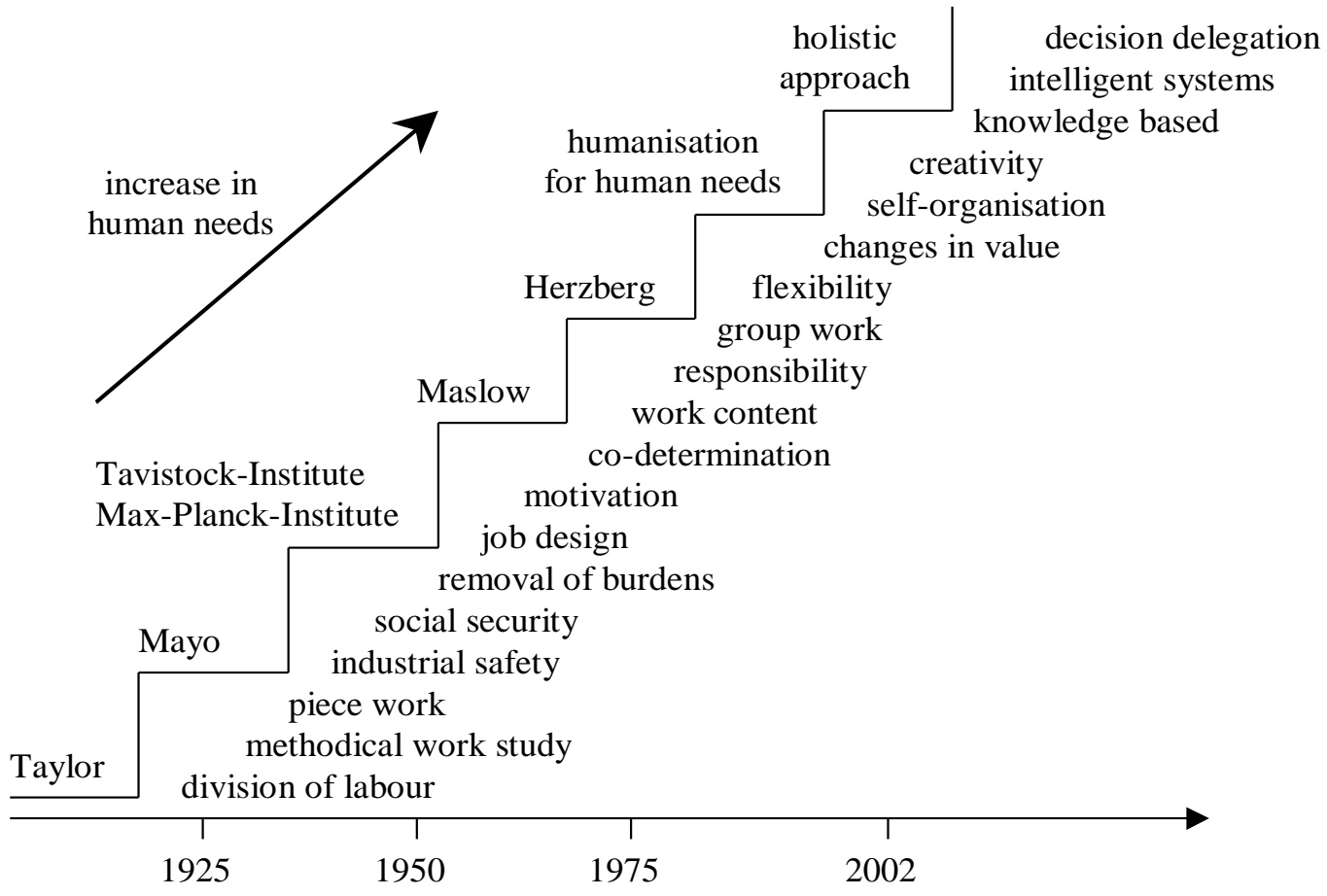

Fig. 1. Development of the social system in production (based on [3]).

The process of evaluation of the human role in manufacturing is also forced by increasing standard of life. Humanisation of the working conditions has very strong influence on the manufacturing organisation, that is moving from piece work system to self-organisation. To be more attractive for workers, most of companies had to introduce new, more holsitic approaches in work organisation (fig.1). 


\section{Human factor in advanced manufacturing systems}

Manufacturing systems' development is going into direction of high flexibility, low production cost and high product quality. During last years several new manufacturing paradigms were proposed. The most important of them are: Computer Integrated Manufacturing (CIM) [4], Intelligent Manufacturing Systems (IMS) [5], fractal manufacturing [3], bionic manufacturing [6], holonic manufacturing (HMS) [7]. Most of proposed paradigms are focused on manufacturing systems' improvement by development of two factors: information management and human factor. The ideas like Intelligent Manufacturing Systems (IMS) combine the latest achievements in various directions and put significant stress on the problem of artificial intelligence supported by machine operators. Similarly, the idea of Holonic Manufacturing Systems is focusing on application of the idea of semiautonomous agents and decentralised decision process in manufacturing control. Machine's operators working in holonic system should focus their activity on solving of complex problems [8]. Fractal and bionic manufacturing ideas propose manufacturing systems' performance improvement by putting stress on work organisation factors based on autonomous groups. In Computer Integrated Manufacturing an important role plays a human operator as well [4]. All of those new manufacturing paradigms aim at building the so called advanced manufacturing systems. In such systems several factors decide about success: technology, information processing and human factor. Moreover, those factors must coexist together. One of the most crucial and still not enough appreciated part in this combination is co-operation of technical systems and human operator.

\section{Human behaviour in manufacturing systems}

The machine or process control and manufacturing management are two general kinds of human work that can be distinguished in manufacturing. People working in manufacturing must co-operate with two different kinds of computer based technical systems: information systems supporting management and machine or process control systems. Generally, the management systems are responsible for decision taking and data management. The control systems are responsible for physical resources action and supervision. On the manufacturing control level the most important things are [9]:

- large number of resources' functions

- multiplicity of tools fixtures and material types 
- highly coupled interaction between resources and its components

- disturbances occurrence, that reduce the ability of the machine or cell

The most important problems on the management level are:

- large number of decision parameters and data

- $\quad$ significant number of highly coupled decision parameters

- behaviour of the controlled system is hard to predict

- disturbances occurrence, that reduce the ability of the system

Tasks performed on pointed levels are different, however man-machine co-operation is in both cases realised mainly by computer based information systems. Such systems should offer as much support for operator as possible. It should allow to move operator activity from simple nearly instinctive work to complex problems solving based on the knowledge and experience.

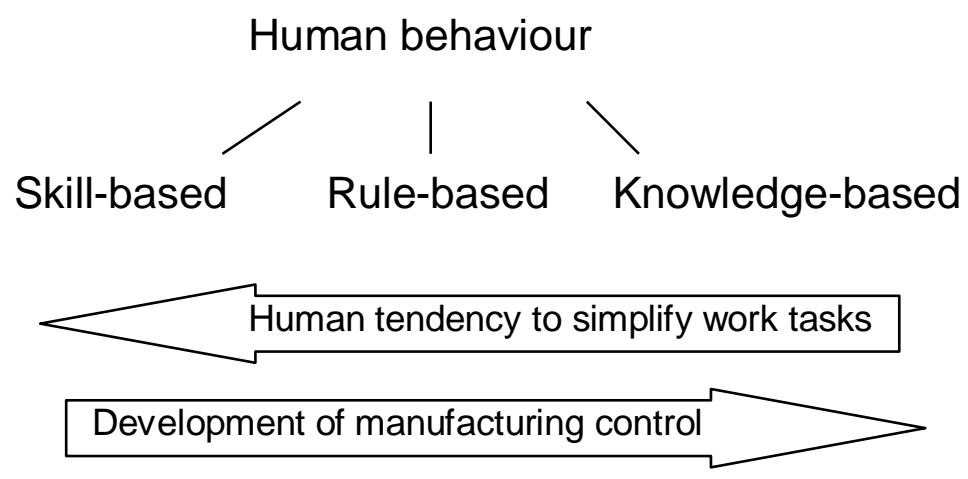

Fig. 2. Three basic kinds of human behaviour.

Rasmussen in his theory of man-machine systems pointed three human behaviour levels [10][11]:

- Skill-based behaviour: well learned, sensory motor behaviour. It is analogous to nearly instinctive hand and foot actions while driving a car.

- Rule-based behaviour: actions triggered by a certain pattern of stimuli. These actions can be executed by a computer, using "if-then" algorithm to initiate an appropriate response.

- Knowledge-based behaviour: responding to new situations. "High-level" situation assessment and evaluation, consideration of alternative actions in the light of various goals. (taking decisions and multifactor scheduling of actions). 
The first two types of actions are based mainly on almost automatic reaction of man on new situation. They do not require to use mental resources. According to the research, human operators are still trying to move their action towards the rule and skill based levels. It allows them to free the mental resources, to meet new situation at the full capacity of their knowledge based behaviour [12]. The knowledge-based behaviour requires to use the mental resources supported by proper knowledge and experience.

Basing on this model, we can sharply see that the control systems can replace the man in skill and rule based behaviour. It allows to improve the system productivity by increasing the quality of process control by moving the human operator from "simple" functions to complicated problems solving. The research is carried now to elaborate the control systems that would be able to support or even replace human operator in some knowledge based activities [13]. Now, most of those activities can only be supported by additional knowledge based systems. Implementation of various solutions based on artificial intelligence and experience from solved similar situations to support human decision process is possible.

\section{Manufacturing systems performance}

Improvement of manufacturing systems performance should based on development of both technical and social systems. The productivity increasing programs based on well know ideas like: KAIZEN, Total Quality Management (TQM), 5S, Total Productivity Maintenance (TPM), have to take into account the human factor to be successful. Properly designed information flow, man-machine and man-computer systems can not be effective without properly developed, suited to local conditions work organisation system. The research done by Udo [14], who analysed the data collected from almost hundred United States manufacturing companies to investigate the relation between human factor and the success of advanced manufacturing systems, has confirmed this problem.

Work organisation supported by computer based information systems should allow to integrate the management levels, to make the organisation more "flat", according to Lean Management ideas. Such an approach allows for appreciation and supporting of machine operators, that usually are the closes persons to the company core business [9]. Improvement of manufacturing systems' performance requires efficient management. The work organisation systems supported by motivation systems can play an important 
role in this process. Managers and machine operators have to be supported by proper information systems and by Decision Support Systems [15]. They can utilise the Artificial Intelligence achievements as well.

The important approach in the field of work organisation, man-machine co-operation and manufacturing systems' performance improvement is the socio-technical design idea and process oriented company organisation [16].

\section{Socio-technical design approach for advanced manufacturing systems development}

The socio-technical approach to system design was introduced by The Tavistock Institute of Human Relation in London at the beginning of fifties. The idea of this approach was to eliminate the negative influence of technical systems on the social system in production [17].

The socio-technical design idea is based both on the experience of one of the sociology approaches called socio-technics and theory of systems design. The first formulation of the socio-technics theory has been done by L. Pietrazycki in 1893. In this early years he wrote: "It deals with the complicated matter of changing social motivation. It concerns the gradual transformation of the human race through elimination of thousands of dissonances and disharmonies. It intends to do so by adjusting the transformation to a new rational basis. This should be done with the utilisation of a scientific approach and with an understanding of casual relationships" [18]. The socio-technical approach was further developed by a number of humanistic scientists for better description or manipulation of human being.

The first application of the socio-technics in manufacturing was done by Eric Trist, the founder of the Tavistock Institute in London [19]. In the Institute, which worked in the field of the applied behavioural science, he developed the concept of the sociotechnical system [20]. The investigation done by him has shown that most of the industry's problems had resulted from introduction of significant changes in technical systems without adequate attention on its impact on the social structure [21].

The first experiments of the socio-technical design idea implementation were provided in coal mines in England, in fifties. It confirmed, that the socio-technical approach allowed to organise work better, to avoid bad impact of the technical system on the social system. After finishing the experiment in English mines, the developed idea was implemented in Scandinavia, where the concept of a socio-technical system 
based on self-managing groups has been created. It was based on clear ethical principles to increase the ability of the individual to participate in decision taking and thought this to increase employee motivation. It also allowed to decentralise the decision process, which resulted in the system robustness increase.

According to socio-technical principles, managers are advised to tell work groups what to do, but not how to do. Their power should be based on co-operation and help, not only on authority. The knowledge and skills should be in the working group. Group elaborates its ways of work with support of managers. They can differ from each other because each group decides on approach that would enable them to provide optimal results with particular focus on a quality. It is important that the idea comes from the working group and is accepted by managers to avoid misunderstandings.

The results of these experiments allowed to develop the number of principles for socio-technical design:

1. The principle of minimum critical specification - tell employees what to do, but not how to do it.

2. The principle of variance control - problems must be corrected as close to the point of origin as possible and preferably by the group that caused them.

3. The principle of multiskilling - give individuals a range of tasks including some routine and some challenge.

4. The principle of boundary management - identify boundaries between groups and functions by looking for discontinuities of time, place and product development, or changes in the group responsible for action. Ensure these boundaries are well managed and that the people on them have the information necessary to pass the product smoothly to its next transformation stage.

5. The principle of information flow - information system should be designed in such a way that information goes directly to the place where action is to be taken or to the source that originated it.

6. The principle of design and human values - an important objective of organisational design should be to provide high quality of working life for employees. For example: the need to be able to learn on the job, the need for an area of decision taking, the need to relate work to social life, the need to feel the job leads to a desirable future. 
7. The principle of incompletion - the need to recognise that design is an ongoing and iterative process.

The socio-technical approach can be applied in all organisations in which manpower co-operates with technical systems. It seams that it is especially suitable for manufacturing systems work organisation. Presently, the company needs proper information system for management and for manufacturing process control support to work efficiently. Introduction of such systems very often requires a transformation of the organisation structure. In fact, in every company three kinds of systems exist: economic, technical and social system. All of them need to be reorganised and adapted to the new situation, when introducing complex information system. Very often the reorganisation of manufacturing and introduction of information systems fail because of the minor problems like motivation misunderstandings or fear of changes [22]. Such problems arise because of the poor interplay between technical and social systems. The solution for this kind of problems can be application of the socio-technical approach in the form of something like a unified framework to guide the implementation process [23][24]. Such a framework, based on the socio-technical principles described above, should allow to solve most of problems arose on bounders of each of the three systems in a company.

\section{Socio-Technical Systems Theory - practical utilisation}

Basing on principles of the socio-technical design elaborated by Trist several years ago the Socio-Technical Systems Theory (STS) has been proposed [25]. The main idea of STS is an integration of the social requirements of people doing the work, with the technical needs to allow the system to work efficiently. These two aspects must be considered independently, because arrangements optimal for one may not be optimal for the other. However, they should be optimised together and some trade off can be done to find the best solution [21].

Many people contributed to development of the STS theory. The significant stress was put on practical utilisation. The research in this direction was carried in Europe by: Dutch Maastricht Economic Research Institute on Innovation and Technology (MERIT), Swedish Work Environment Fund's LOM program that involves more then 100 companies and the Work Research Institute in Oslo. The most known organisations and research centres among the organisation in North America are Alcan, the American 
Productivity Center in Huston, AT\&T, Best Foods, Clark Equipment, Cummins Engine, Digital Equipment Company, Exon, Ford, General Foods, General Motors, Harman International, Hawellet Packard, Inland Steel, LTV Steel, Mead Paper, Procter and Gamble, Shell Oil, Sherwin-Williams, Tektronix, TRW, Weyerhauser, the Work in America institute in New York, Xerox, Zilog and various U.S. and Canadian government agencies, such as the Total Quality Management program of the U.S. Defence Department [21].

Most of research effort on the socio-technical approach utilisation in manufacturing systems organisation was done by United States' companies and research institutes. It seams that in Europe the advantages of the idea are not known very well. Some researchers attempt to develop new work organisation concepts that would meet today's needs, forgetting about good ideas developed almost 50 years ego. Those approaches, like socio-technical design should be taken into account when we work on new conceptions of work organisation and human-technical system interactions.

\section{Human decision quality}

The control of system is strongly connected with the decision quality. It has significant influence on the system proper work and its performance. In manufacturing systems the decisions can be divided into two kinds: decisions taken by automated control systems and decisions taken by human operator or manager. In most of manufacturing systems men and women are responsible for knowledge and experience based decisions. Even in highly automated systems human operator must be the part of the management system, because even the highly advanced control can not handle all possible events [9]. Simple control decisions based on if-else algorithms for system control and managing with the most common disturbances should be realised automatically by control systems.

The discrete production, like manufacturing, is difficult to control, because of its complexity. Parunak [26] points five factors that make it difficult: desirability, stochasticity, tractability chaos and decidability.

Desirability it is hard to cope with the wishes of managers taking into account the management of the whole data set.

Stochasticity uncertain events, such as breakdowns or interference, decrease the ability of the management system to respect production aims. 
Tractability algorithms for production management take too much time to run.

Chaos chaotic behaviour characterises discrete production structures. The sensibility of the initial conditions of a discrete production process amplifies differences between closed states of the system, leading to different behaviours.

Decidability it is hard to make decisions based upon the analysis of the behaviour of a discrete production system.

Pointed factors decide that the management decisions in manufacturing are complex and difficult to evaluate. Moreover, in discrete production large number of decisions concern problems like brake downs. They appear quite often, but usually they are not standard. The unique knowledge and experience based decision have to be taken to solve such problems. Very often the decisions are taken under high stress, because of high cost of production stop or delay.

It is very important to analyse the consequence of decision quality, depending on the human behaviour. Such an analyse can be useful in two main cases: on-line decision evaluation as a support for decision maker, and off-line for evaluation of taken decision, especially in the case of dangerous or costly wrong decisions. The off-line analyse can be also used to study weak points of the management or control systems in the case of their improvement from the decision quality point of view.

Modelling of the human decision quality was the aim of some research projects. Most of them focused on human errors in non-production areas like nuclear plants, air transport, military, large accidents analysis, etc. [27]. Most of those work and proposed analysis methods are poorly documented, their results depend on expert intuition and they are not as useful as they could be. According to Johnson it is the result of the fundamental characteristics of human perception, physiology and cognition [28].

The problem of human decision quality has to be taken into account in manufacturing systems and their components' designing, although the modelling and strict evaluation of the decision quality based on it, is difficult to do. Advanced systems designers should remember that the most complex and costly decisions are taken by a man. The systems should be designed in such a way to reduce the probability of errors occurrence. Man-machine interfaces and computer systems interfaces have to present only the most important information in simple and easy way to understand. Knowledge sources, easy to access can be useful in the case of complicated and rarely occurring problems. The decision support, suggesting the best solutions can be useful as well. 
The decision quality analysis can be helpful in computer systems design, manufacturing systems improvement and personnel training. It can show weak points on which the stress should be put to improve the manufacturing system performance.

\section{Artificial Intelligence in man-machine systems}

The advance in production is focused on new manufacturing methods' application and on improvement of control and management by replacing skill based and rule based human activities by automated machines and systems. Progressive manufacturing automation is mainly driven by increase in human needs, high repeating quality of products, continuous decrease in production cost, shortening of production series.

Nowadays, in advanced manufacturing systems human operator should be focused only on taking knowledge and experience based decisions, that can not be replaced by present computer systems. The next step is to support a man by artificial intelligence in this field. Research on implementation of Intelligent Systems (IS) in manufacturing are going in three directions: support of a man by IS, replacing of a man by IS and extending of control systems possibilities into new fields.

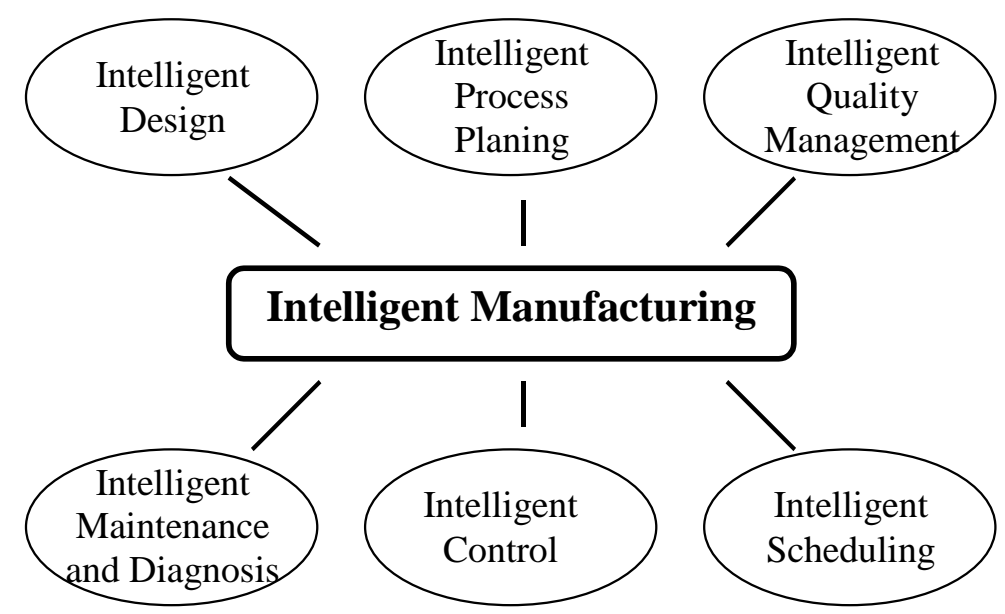

Fig. 4. Components of an intelligent manufacturing system (based on [29]).

Intelligent systems can be used in manufacturing management and as a support for machine operators. The idea is not to eliminate a man, but to support him or her by knowledge required to take the best decision, and by examples of proper solutions used in similar situations. The solutions elaborated by specialist can be suggested as well. The main advantages of such an approach are: decrease in operator or manager mental workload, possibility to use highly specialised knowledge and experience suitable for 
particular problem and possibility of analyse of large data amount with complex criterions. Decreasing in decision dependency on decision maker mental model is important as well.

Replacing of some decision activities of human operator and extending possibilities of control systems by solutions based on artificial intelligence are other fields of intelligent system implementation. Intelligent control can be used in various places of manufacturing systems. Such solutions are very useful for control of machines and processes in which building of formal control model is impossible, or there is too large number of influencing parameters, that can not be measured precisely to calculate the optimal solution. Intelligent control systems used in those areas allow for both elimination of boring control activities from operator work and to apply automatic systems in places impossible to control in traditional way. Examples of IS applications in manufacturing are Intelligent Machine Control [13], Intelligent Process and Machine Supervision [30], Intelligent Scheduling [31].

Application of Artificial Intelligence techniques in manufacturing has been the research subject in the last two decades. It was strongly connected with development of computer techniques. Meziane described main solutions based on Artificial Intelligence [29]. They were: knowledge-based systems, neural networks, case-based reasoning, genetic algorithms and fuzzy logic. The knowledge-based systems (KBS) are the oldest approach. They incorporate human knowledge about particular area, usually based on expert knowledge, so the system can automatically replicate aspects of the best practice. Recently, artificial intelligence is based on neural networks (NN), case-based reasoning (CBR), genetic algorithms (GA) and fuzzy logic. Neural networks are based on ideas about how the brain may work. Fuzzy logic allows for representation and processing of uncertain or vague information. Genetic algorithms use ideas from population genetics for solving complex global optimisation problems. Case-based reasoning is the intelligent component of the system that contains past problems and the solutions applied in the past.

From the human point of view Intelligent Systems allow to support the decision process by suggesting the best solutions. The IS allows also for control of process that couldn't be controlled in traditional way. It seams that the Artificial Intelligence based solutions can make a significant contribution in manufacturing systems development and their performance increasing, by improvement of the decision and control quality. 


\section{Conclusions}

Manufacturing systems performance depends on proper co-operation of two systems: technical system and social system. In highly competitive environment, production companies have to develop both factors to reach the success. The role of employees in advanced manufacturing systems is even higher then in the past, because of more complicated systems and higher losses when wrong decision is taken. The employees' requirements have changed significantly as well.

The changing role of managers and machine operators was presented in the paper. The behaviour description can help in machine control systems and computer based information systems development. The Socio-Technical Design idea is able to support the advanced manufacturing systems' performance improvement, by helping proper design and development of the technical-social systems co-operation. At the end the decision quality and Intelligent Systems implementation as a support for employees' working in production were discussed.

\section{References}

1. Mikler J., Hadeby H., Kjellberg A., Sohlenius G. „Towards Profitable Persistent Manufacturing. Human Factors in Overcoming Disturbances in Production Systems", The International Journal of Advanced Manufacturing Technology, Springer-Verlag London 1999, 15 p.749-756.

2. Karuppan C.M. "How streeful is the automated shopfloor?", Benchmarking for quality Management \& Technology, Vol. 2, No 4, 1995, pp. 27-40.

3. Warnecke H.J. "The Fractal Company A revolution in Corporate Culture”, SpringerVerlag 1993.

4. Nagalingam S.V., Lin G.C. "Latest developments in CIM", Robotics and Computer Integrated Manufacturing, 15 (1999), pp. 423-430.

5. Kusiak A. "Intelligent Manufacturing Systems", Prenticc Hall, Englewood Cliffs. NJ (1990).

6. Okino N. "A prototyping of bionic manufacturing system", international Conference on Object-oriented Manufacturing Systems, May 3-6, Department of Manufacturing Engineering, University of Calgary, Alberta, Canada, 1992, pp. 297-302. 
7. Wyns J., Langer G. "Holonic Manufacturing Systems described in plain text, IDEF0, and Object-Oriented methods", Proceedings of the First International Workshop on Intelligent Manufacturing Systems, Lausanne, 15-17 April 1998, p.13-28.

8. Oborski P., Szafarczyk M. „Organisation and Control at the Basic Manufacturing Level with Human-Computer Integration”, Advances in Manufacturing Science and Technology, Vol. 25, No. 1, 2001, p.5-15.

9. Trentesaux D., Moray N., Tahon C. "Integration of the human operator into responsive discrete production management systems", European Journal of Operational Research, Vol. 109 (1998), pp. 342-361.

10. Rasmussen J., Goodstein L. "Decision support in supervisory control”, Pre-prints of Analysis, Design and Evaluation of Man-Machine Systems, $2^{\text {nd }}$ IFAC/IFIP/IFORS/IEA Conference, Varcsc, Italy 10-12 September 1985, pp. 33-42.

11. Corbett J.M., Rasmussen L.B., Rauner E. "Crossing the Border: The social and Engineering Design of Computer Integrated Manufacturing Systems", SpringerVerlag, Great Britain, 1991.

12. Stahre J., "Evaluating human/machine interaction problems in advanced manufacturing”, Computer Integrated Manufacturing Systems, Vol. 8, No 2 p. 143$150,1995$.

13. Lei M., Yang X., Tseng M., Yang S. "Design an intelligent machine center strategy and practice", Mechatronics 8 (1998), pp. 271285.

14. Udo G., Ebiefung A. "Human factors affecting the success of Advanced Manufacturing Systems", Computers \& Industrial Engineering, 37(1999), p.297-300.

15. Barthelemy J.P., Bisdorff R., Coppin G. "Human centered process and decision support systems", European Journal of Operational Research, Vol. 136 (2002), pp. 233-252.

16. Oborski P., Buczacki A. „Process oriented organisation and human factors in computer integrated manufacturing", Proceedings of the International Conference: Computer Integrated Manufacturing 2001 - CIM'01, Zakopane 7-8.03.2001.

17. Mumford E. "New treatments or old remedies: is business process reengineering really socio-technical design? ”, Journal of Strategic Information Systems, 1994, 3(4), p. 313-326.

18. Podgorecki A. "Socio-technics: basic concepts and issues", Knowledge In Society, Spring90, Vol. 3 Issue 1, p. 62-84. 
19. Fox W.M "An interview with Eric Trist, father of the sociotechnical systems approach", Journal of Applied Behavioural Science, Jun90, Vol. 26 Issue 2, p.259280.

20. Trist E., Bamforth K. "Some social and psychological consequences of the long wall method of coal getting", Human Relation 4, 1951, p. 3-38.

21. Fox W.M "Sociotechnical system principles and guidelines: past and present", Journal of Applied Behavioural Science, Mar95, Vol. 31 Issue 1, p. 91-106.

22. Jacobson I., Ericsson M., Jacobson A. "The object advantage - business process reengineering with object technology”, Addison-Wesley Publishing Company 1995.

23. Shani A.B., Sena J.A. "Information technology and the integration of change: sociotechnical system approach”, Journal of Applied Behavioural Science, Jun94, Vol. 30 Issue 2, p. 247-271.

24. Plavia S.C., Sharma R.S., Conrath D.W. "A socio-technical framework for quality assessment of computer information systems", Industrial Management \& Data Systems, 101/5 [2001], pp. 237-251.

25. Jones P.M. "Designee for operations: towards a sociotechnical systems and cognitive engineering approach to concurrent engineering", International Journal of Industrial Ergonomics, 16, 1995, p. 283-292.

26. Parunak V.H.D. "Characterising the manufacturing scheduling problem", Journal of Manufacturing Systems 10 (3), 1991, pp. 241-252.

27. Cacclabue P.C., Cojazzi G. "An integrated simulation approach for the analysis of pilot-aeroplane interaction”, Contorl Eng. Practices, Vol.3, No.2, pp.257-266, 1995.

28. Johnson C. "Why human error modelling has failed to help systems development", Interacting with Computers, 11 (1999), p. 571-524.

29. Meziane F., Vadera S., Kobbacy K., Proudlove N. "Intelligent systems in manufacturing: current developments and future prospects", Integrated Manufacturing Systems, 11/4 [2000], pp. 218-238.

30. Sokolowski A., Kosmol J. "Selected examples of cutting process monitoring and diagnostics", Materials Processing Technology, 113 (2001) pp. 322-330.

31. Xue D., Sun J., Norrie D. “An intelligent optimal production scheduling approach using constraint-base search and agent-based collaboration”, Computers in Industry 46 (2001), pp. 209231. 